\title{
The effect of surgery on lung volume and conventional monitoring parameters in ventilated newborn infants
}

\author{
H. Proquitté*, O. Freiberger*, S. Yilmaz*, C. Bamberg" ${ }^{\#}$ P. Degenhardt ${ }^{\dagger}$, C.C. Roehr*, \\ R.R. Wauer* and G. Schmalisch*
}

ABSTRACT: In newborn infants, thoraco-abdominal surgery is a serious intervention with respect to gas exchange and lung mechanics. This prospective clinical study compared surgery-induced changes in functional residual capacity (FRC) and ventilation inhomogeneity (VI) indices with changes in conventional monitoring parameters.

Of 29 ventilated newborns (mean weight $2,770 \pm 864 \mathrm{~g}$ at surgery), 13, nine and seven underwent thoracic, abdominal or congenital diaphragmatic hernia (CDH) surgery, respectively. The multiple breath washout (MBWO) technique using heptafluoropropane as tracer gas (Babylog ${ }_{\circledR}$ 8000; Dräger, Lübeck, Germany) was performed $<6 \mathrm{~h}$ before surgery, 22-24 $\mathrm{h}$ after surgery and $<6 \mathrm{~h}$ before extubation. Gas exchange, respiratory mechanics, $\mathrm{FRC}$ and $\mathrm{VI}$ index data were recorded.

Thoraco-abdominal surgery resulted in changes to FRC and VI indices in a procedure-specific manner; however, these changes were not reflected in conventional mechanical or ventilatory monitoring parameters. FRC decreased in non-CDH infants, while FRC increased and VI indices decreased in CDH infants. Despite improvements, the differences in FRC and VI between CDH and non-CDH infants indicated persistent impaired lung function in CHD infants.

MBWO can be advantageously used to measure the effect of surgery on the lung. While FRC and $\mathrm{VI}$ indices changed following surgery, conventional monitoring parameters did not.

KEYWORDS: Congenital diaphragmatic hernia, lung volume, mechanical ventilation, multiple breath washout, newborn infant, thoraco-abdominal surgery

urvival in newborn infants following corrective surgery for serious cardiac [1, 2] or abdominal wall defects [3] or for congenital diaphragmatic hernia $(\mathrm{CDH})[4]$ has improved over the last decade. Nevertheless, opening the thoracic cavity and/or abdominal wall remains a significant intervention with respect to temporary alterations in gas exchange and lung volume.

In addition to ventilator monitoring, blood gas analyses and repeated radiographs are usually performed in ventilated infants to monitor clinical development. Meanwhile, commercial equipment is available to assess lung aeration by measuring functional residual capacity (FRC) and ventilation inhomogeneity (VI) indices [5-7]. This noninvasive method is based on the multiple breath washout (MBWO) measurement technique using a tracer gas [8]. However, the equipment used for simultaneously measuring airflow and molar mass of the breathing gas is generally bulky and cumbersome for routine applications in intubated newborns or premature infants, and requires significant floor space [9]. We have recently validated a prototype of an extended neonatal ventilator for MBWO analysis in small ventilated piglets [10]. This apparatus uses a miniaturised lightweight gas sensor and heptafluoropropane (HFP) as the tracer gas.

We hypothesised that this technique can be advantageously used in a clinical setting to measure the effect of surgery on the lung. The aim of the present prospective clinical study was the use of the HPF-MBWO technique to investigate the effect of thoraco-abdominal surgery on the lung, and to compare the changes in FRC and VI indices with the changes in conventional monitoring parameters.

\section{MATERIALS AND METHODS \\ Patient characteristics}

This prospective clinical study was performed in the intensive care unit of the Clinic of Neonatology, Charité Universitätsmedizin Berlin (Campus
AFFILIATIONS

${ }^{*}$ Clinic of Neonatology,

\#Dept of Obstetrics, and - Clinic of Paediatric Surgery, Charité Universitätsmedizin Berlin, Berlin, Germany.

CORRESPONDENCE H. Proquitté

Clinic of Neonatology, CCM Charité Universitätsmedizin Berlin Schumannstr. 20/21

10117 Berlin

Germany

E-mail: hans.proquitte@charite.de

Received:

April 072009

Accepted after revision:

Sept 082009

First published online:

Sept 242009 
Mitte, Berlin, Germany). 62 newborn infants born between November 2006 and June 2008 and requiring surgery were potentially eligible for the study. The inclusion criteria were anticipated surgery and written parental consent. Due to the equipment apparatus dead space volume ( $V \mathrm{D}, \mathrm{app})$ of $4.5 \mathrm{~mL}$, only infants with a tidal volume $(V \mathrm{~T})>10 \mathrm{~mL}$ as measured after intubation by the Babylog ${ }_{\circledR}$ (BL) 8000 (Dräger, Lübeck, Germany) were included. 33 infants were excluded due to no requirement for mechanical ventilation after surgery $(n=10)$, measurements not able to be performed according to the protocol $(\mathrm{n}=11)$, a $V \mathrm{~T}<10 \mathrm{~mL}(\mathrm{n}=7)$, or parents refusing to give consent $(n=5)$.

The remaining 29 infants were divided into three groups according to the field of surgery: 13 infants had thoracic operations (congenital heart disease or oesophageal atresia), nine infants had abdominal surgery (gastroschisis, omphalocele or volvulus) and seven infants had $\mathrm{CDH}$ where both cavities were opened. The study was approved by the Ethical Committee of the Charité Universitätsmedizin Berlin.

\section{Equipment for FRC measurement}

FRC was measured using a modified BL 8000. Briefly, a previously described infrared HFP sensor [10] was placed between the flow sensor of the BL 8000 and the endotracheal tube (ET). The constant flow of the ventilator ranged from 8 $16 \mathrm{~L} \cdot \mathrm{min}^{-1}$ depending on the ventilatory pressure required. Using a mechanical valve, medical grade HFP (Solvay, Hannover, Germany) from a gas cylinder was fed into the inspiratory limb of the ventilatory circuit to achieve a constant HFP concentration of $0.8 \%$. FRC was calculated according to the MBWO technique using the flow signal (flow sensor, BL 8000) and the concentration signal (HFP sensor) by a software developed by Dräger. The lung clearance index (LCI) was calculated as the number of turnovers required to lower the end tidal tracer gas concentration to $1 / 40$ th of the starting concentration. The first three moments $\left(\mathrm{M}_{0}, \mathrm{M}_{1}, \mathrm{M}_{2}\right)$ of the washout curve and moment ratios $\left(\mathrm{M}_{1} / \mathrm{M}_{0}, \mathrm{M}_{2} / \mathrm{M}_{0}\right)$ and the alveolar mean dilution numbers $\left(\mathrm{AMDN}_{1}, \mathrm{AMDN}_{2}\right)$ were derived from calculations that commenced at the 0 th breathing cycle and ended if concentrations fell below 1/40th of the initial concentration. All VI indices were calculated by purpose-built software using the data of the BL 8000, as described previously [11]. The time delay between flow sensor signal and HFP concentration was compensated for electronically. The sample rate was $125 \mathrm{~Hz}$ and all signals were stored.

FRC measurements were commenced manually and stopped automatically after $\mathrm{N}$ cycles when the amount of ventilated alveolar air $(V \mathrm{~T}-V \mathrm{D}) \cdot \mathrm{N}$ exceeded the calculated FRC by a factor of 10. In each case, the minimum number of cycles was set at $\mathrm{N}=40$. VD was calculated from the HFP signal by the Dräger software using the Bohr equation. An electronic two-point calibration of the HFP sensor using internal light signals and a one-point flow sensor calibration of the BL 8000 as recommended by the manufacturer was performed prior to every FRC measurement, and the equipment was also checked using a lung model before each measurement [10].

\section{Protocol}

All measurements were performed with the patient in a supine position at three defined time-points: within $6 \mathrm{~h}$ before surgery, 22-24 h after surgery, and within $6 \mathrm{~h}$ prior to extubation.

The study protocol did not specify any ventilatory parameters, except that the mode had to be conventional or synchronised intermittent mandatory ventilation (no high frequency ventilation). Ventilation and inspiratory oxygen fraction $\left(F \mathrm{I}, \mathrm{O}_{2}\right)$ were adjusted aiming for an arterial carbon dioxide tension $\left(\mathrm{Pa}, \mathrm{CO}_{2}\right)$ of between 35 and 55 Torr $(4.67-7.33 \mathrm{kPa})$ and normoxia according to clinical diagnoses (e.g. cyanotic heart failure). For each FRC measurement, respiratory frequency $(f \mathrm{R}), V \mathrm{~T}$, ET leakage and respiratory compliance (Cresp), which was calculated by linear regression analysis, were taken from the BL 8000.

Besides MBWO parameters (FRC, LCI, $\mathrm{M}_{1} / \mathrm{M}_{0}, \mathrm{M}_{2} / \mathrm{M}_{0}$, $A M D N_{1}$ and $A M D N_{2}$ ), ventilatory pressures (peak inflation pressure (PIP) and positive end-expiratory pressure (PEEP)) and blood gases were recorded. Additionally, $\mathrm{FI}, \mathrm{O}_{2}$, arterial oxygen tension $\left(\mathrm{Pa}_{\mathrm{a}} \mathrm{O}_{2}\right) / \mathrm{FI}, \mathrm{O}_{2}, \mathrm{~Pa}_{1} \mathrm{CO}_{2}$, arterial oxygen saturation $\left(\mathrm{Sa}, \mathrm{O}_{2}\right)$, blood pressure and heart rate (M1166A; Philips Medical Healthcare, Hamburg, Germany) were recorded at each of the three scheduled time-points for evaluation of circulatory parameters following surgery. Data obtained from patient charts included gestational age, birth weight, sex, multiple births, pre-natal administration of steroids, mode of delivery and Apgar scores at 1 and $5 \mathrm{~min}$.

FRC measurements were performed identically at each of the three scheduled time-points. After preparation and calibration of the equipment with identical adjustment of the modified BL 8000, the ET of the infant was clamped to avoid FRC destabilisation. Within $5 \mathrm{~s}$, the modified BL 8000 was connected and a stabilisation period of $15 \mathrm{~min}$ was allowed with continuing mechanical ventilation. Arterial blood samples for blood gases (ABL 800Flex; Radiometer Medical ApS, Bronshoj, Denmark) were then taken and FRC measurements were commenced with an HFP wash-in procedure (FRCwash-in) and a consecutive washout procedure (FRCwashout). Such a cycle was accepted for evaluation and a mean value of FRCwash-in and FRCwashout was calculated if the deviation between FRCwash-in and FRCwashout was $<20 \%$ and the $V$ T was $>10 \mathrm{~mL}$ due to the increased $V \mathrm{D}$,app. All lung function measurements were repeated three times for each of the three situations.

\section{Statistics}

$\mathrm{CDH}$ is too rare a diagnosis ( $\sim 1$ in every 3,500 births) for a sample size calculation. A sample size of 22 was calculated only for non-CDH infants as being required to detect a FRC difference of $2 \mathrm{~mL} \cdot \mathrm{kg}^{-1}$ after surgery, assuming a standard deviation (SD) of the FRC differences (based on a pilot study) of $3.8 \mathrm{~mL} \cdot \mathrm{kg}^{-1}$, and an alpha error of 0.05 and a beta error of 0.1 .

Patient characteristics between the patient groups were compared using Chi-squared tests and ANOVA, as appropriate. Apgar scores, age at time of surgery and duration of intubation and surgery are expressed as median and range and were compared using the Kruskal-Wallis test. All physiological parameters are presented as mean $\pm \mathrm{SD}$ in tables and mean $(95 \%$ CI) in figures. Differences between patient groups were tested using ANOVA with Student-Newman-Keul's post hoc test. ANOVA for repeated measurements with Dunnett's post 
hoc test (comparison with baseline) was used to analyse parameter development. Bonferroni correction of the p-value for multiple within and between group comparisons was used. Statistical analysis was performed using Statgraphics Centurion software (version 15.0; Statpoint Inc., Herndon, VA, USA) and GraphPad PRISM version 4 (San Diego, CA, USA). Statistical significance was defined as a $\mathrm{p}$-value $<0.05$.

\section{RESULTS}

\section{Subjects}

The three patient groups (i.e. thoracic, abdominal and $\mathrm{CDH}$ surgery) were similar in terms of pre-operative patient characteristics (table 1). Only four (13.8\%) out of 29 infants had received pre-natal steroids, while two (6.9\%) out of 29 had undergone surfactant treatment. While the mean bodyweights were similar for all three groups, there was a wide scatter in the time of surgery without statistically significant differences in the median after Bonferroni correction (table 2).

\section{Ventilatory parameters, blood gases and circulatory parameters}

The between-group comparison showed that before and after surgery ventilatory parameters (PIP, PEEP, $f R, V T$, oxygenation index and ventilatory efficacy index), blood gas parameters $\left(\mathrm{Pa}, \mathrm{O}_{2} / \mathrm{FI}_{1} \mathrm{O}_{2}, \mathrm{~Pa}_{2} \mathrm{CO}_{2}, \mathrm{Sa}_{1} \mathrm{O}_{2}\right)$ and circulatory parameters (heart rate, systolic and diastolic blood pressure) were not statistically significant different between the three patient groups. Only in $\mathrm{CDH}$ infants compared with the other two patient groups was $f R$ significantly higher $(\mathrm{p}<0.001)$ before surgery and $V \mathrm{~T}$ significantly lower $(p<0.001)$ before as well as after surgery.

In all three patient groups, the within-group comparison showed no statistically significant effect of surgery on ventilatory, blood gas and circulatory parameters, respectively.

\section{Effect of surgery on lung function}

The pre-operative Cresp and FRC for each patient group are shown in figure 1. In $\mathrm{CDH}$ infants, both parameters were lower, while there were no significant differences between thoracic and abdominal surgery infants. Most pre-operative VI indices were higher in the $\mathrm{CDH}$ infants, whereas there were no significant differences between the other two patient groups (fig. 2).

The development of lung function after surgery differed between patient groups (table 3). There were distinct differences in parameter progression between thoracic, abdominal and $\mathrm{CDH}$ surgery infants. Thoracic surgery resulted in changes in FRC, LCI and moment ratios, while Cresp remained nearly constant. At $24 \mathrm{~h}$ after thoracic surgery, FRC was lower and ventilatory $\mathrm{VI}$ indices, $\mathrm{LCI}$ and $\mathrm{M}_{1} / \mathrm{M}_{0}$ were higher $(\mathrm{p}<0.05)$. Before extubation, all pulmonary parameters returned to baseline values except for $\mathrm{FRC}$, which remained elevated $(\mathrm{p}<0.001)$.

At $24 \mathrm{~h}$ after abdominal surgery, FRC was lower, but recovered to baseline by the time of extubation. Cresp also decreased after abdominal surgery, but only marginally. However, prior to extubation, Cresp exceeded the baseline $(p<0.001)$. No significant differences were observed in the VI indices.

Parameter development differed between $\mathrm{CDH}$ and non-CDH infants. Besides Cresp, there was an improvement in all pulmonary parameters after surgery. Compared with baseline, FRC increased $(\mathrm{p}<0.01)$ and all VI indices (LCI, $\mathrm{M}_{1} / \mathrm{M}_{0}, \mathrm{M}_{2} /$ $\left.\mathrm{M}_{0}, \mathrm{AMDN}_{1}, \mathrm{AMDN}_{2}\right)$ decreased $(\mathrm{p}<0.05)$.

Cresp and FRC were compared between patient groups prior to extubation (fig. 3). There were no significant differences in the infants following thoracic or abdominal surgery. However, despite the trend of increased Cresp and improvement in FRC in $\mathrm{CDH}$ patients, both parameters remained lower compared with the other patient groups. At extubation, there were no significant differences in VI indices between the three patient groups.

\section{DISCUSSION}

Our study has shown that HFP-MBWO is a suitable technique to measure the effect of surgery on the lung. The main finding was that FRC and VI indices measured during mechanical ventilation were more affected by surgery than conventional monitoring parameters. Furthermore, the effect on FRC and VI indices was procedure-specific.

TABLE 1 Patient characteristics at birth

\begin{tabular}{|c|c|c|c|c|}
\hline Subjects n & 13 & 9 & 7 & \\
\hline Gestational age weeks & $36.6 \pm 3.5$ & $34.4 \pm 4.3$ & $37.9 \pm 1.6$ & 0.134 \\
\hline In born $\#$ & $9 / 13(70)$ & $7 / 9(78)$ & $5 / 7(71)$ & 0.905 \\
\hline Male & $9 / 13(69)$ & 3/9 (33) & $4 / 7(54)$ & 0.248 \\
\hline Surfactant & $1 / 13(7.7)$ & $1 / 9(11)$ & $0 / 7(0)$ & 0.678 \\
\hline Apgar $1 \mathrm{~min}$ & $8(2-10)$ & $7(2-9)$ & $5(1-9)$ & 0.078 \\
\hline Apgar $5 \mathrm{~min}$ & $9(3-10)$ & $8(7-9)$ & $7(5-8)$ & 0.149 \\
\hline
\end{tabular}

Data are presented as mean $\pm \mathrm{SD}, \mathrm{n} / \mathrm{N}(\%)$ or median (range), unless otherwise indicated. $\mathrm{CDH}$ : congenital diaphragmatic hernia. ${ }^{\#}$ : infants were born within our hospital in the obstetric unit and were not transferred from another hospital to our unit for surgery; " : reduced total number due to missing data of admitted patients. 


\section{TABLE 2 Patient characteristics at surgery}

\begin{tabular}{|c|c|c|c|c|}
\hline Subjects $\mathbf{n}$ & 13 & 9 & 7 & \\
\hline Age at time of surgery days & $9(1-113)$ & $2(1-103)$ & $2(2-2)$ & 0.022 \\
\hline Duration of surgery min & $145(60-235)$ & $150(45-540)$ & $100(30-120)$ & 0.091 \\
\hline Duration of intubation days & $10.5(3-23)$ & $9.0(4-25)$ & $8.0(6-22)$ & 0.914 \\
\hline
\end{tabular}

The three patient groups were similar with regard to clinical characteristics (tables 1 and 2). The wide scatter in the age of the infants undergoing thoracic and abdominal surgery reflected the diagnosis and the clinical requirements, whereas all $\mathrm{CDH}$ infants underwent surgery on the second post-natal day based on our standard protocol.

Before surgery, lung function measurements were similar for the infants requiring abdominal or thoracic surgery, probably because the lung was only indirectly affected. In contrast, $\mathrm{CDH}$
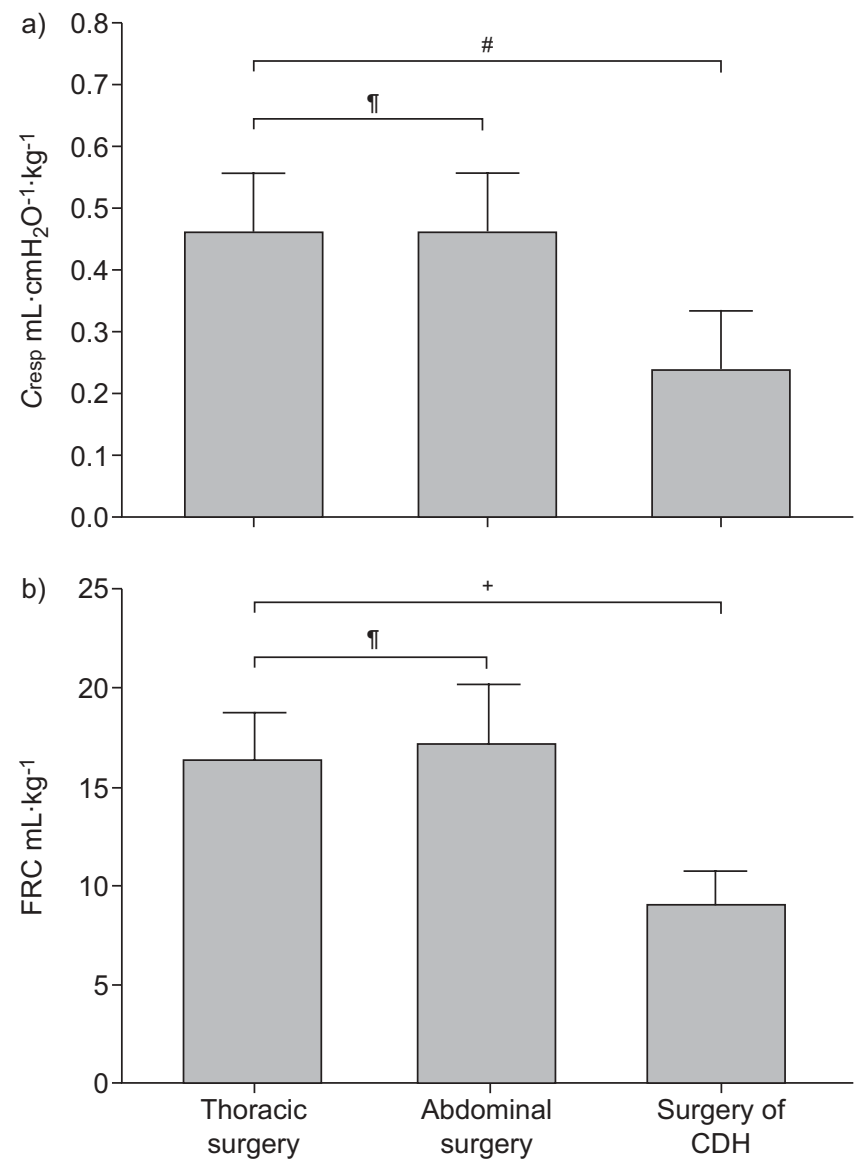

FIGURE 1. a) Respiratory compliance (Cresp) and b) functional residual capacity (FRC) in infants before thoracic, abdominal or congenital diaphragmatic hernia $(\mathrm{CDH})$ surgery. ${ }^{\#}$ : $p=0.001{ }^{\bullet}{ }^{\circ}$ : nonsignificant; ${ }^{+}: \mathrm{p}<0.0001$. infants with impaired pre-natal lung development [12] had lower FRC and Cresp and higher VI indices, indicating impaired ventilation homogeneity. Although lungs in infants requiring abdominal or thoracic surgery are thought to be probably normal, we found both groups had relatively low FRC values $\left(16.38 \pm 4.0\right.$ and $17.12 \pm 3.9 \mathrm{~mL} \cdot \mathrm{kg}^{-1}$, respectively). These observations may be explained by the findings of VON UNGERN-STERNBERG et al. [8] in a study of 14 anesthetised young infants (2.76-7.5 kg; aged 0-6 months) that demonstrated that neuromuscular blockade led to a decrease in FRC from $21.3 \pm 4.7 \mathrm{~mL} \cdot \mathrm{kg}^{-1}$ to $12.2 \pm 4.8 \mathrm{~mL} \cdot \mathrm{kg}^{-1}$, which could be restored by additional PEEP of $3 \mathrm{cmH}_{2} \mathrm{O}$. In our study, PEEP was applied prior to neuromuscular blockade and not changed, and FRC measurements prior to and $24 \mathrm{~h}$ after surgery were performed under neuromuscular blockade.

We found that the effect of surgery on lung function measurements was procedure specific. Within $24 \mathrm{~h}$ after surgery, FRC decreased in infants who underwent thoracic or abdominal surgery, VI indices increased in infants who underwent thoracic surgery, while FRC and VI indices improved in $\mathrm{CDH}$ infants (table 3 ). Few studies on respiratory mechanics in newborn infants measured parameters both

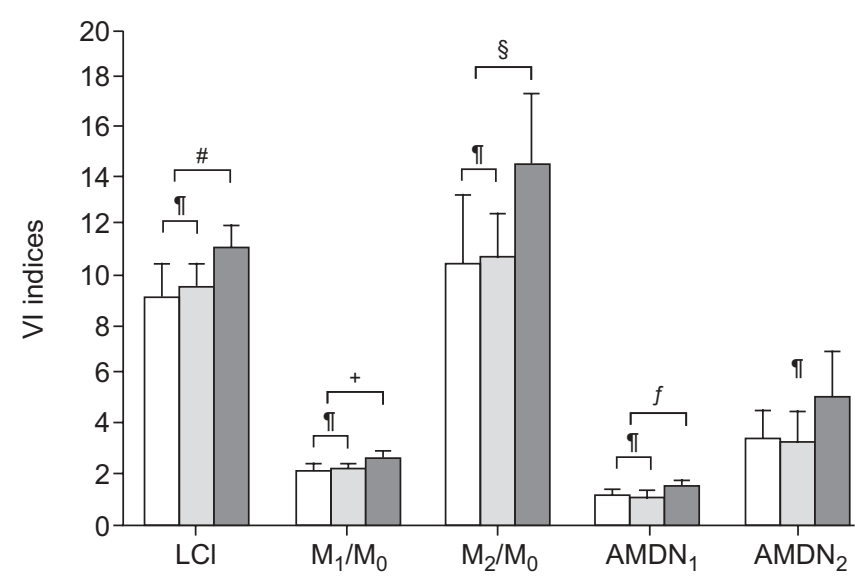

FIGURE 2. Comparison of different ventilation inhomogeneity (VI) indices in infants before thoracic $(\square)$, abdominal ( $\square$ ) or congenital diaphragmatic hernia ( $\square$ ) LCl: lung clearance index; $M_{1} / M_{0}$ : first-to-zeroth moment ratio; $M_{2} / M_{0}$ : second-tozeroth moment ratio; $A M D N_{1}$ and $A M D N_{2}$ : alveolar mean dilution numbers 1 and 2, respectively. ${ }^{*}: p=0.028 ;{ }^{~}$ : : nonsignificant; ${ }^{+}: p=0.02 ;{ }^{\varsigma}$ : $p=0.033 ;{ }^{f}: p=0.01$. 
pre- [13] and post-operatively [14, 15]. DiMITRIOU et al. [16] demonstrated in infants with abdominal wall defects that primary closure and surgical repositioning of the herniated viscera into the abdomen was associated with deterioration of Cresp. Since this observed effect was only temporary, they interpreted the decrease in Cresp with an increase in intraabdominal pressure. While it appeared that the same Cresp trend was observed in the abdominal surgery infants in our study, the findings did not reach statistical significance.

The differences in lung function measurements between $\mathrm{CDH}$ and non-CDH infants were not the result of any differences in volume load, duration of operation or anaesthesia, which were similar for all three patient groups (table 2). In five patients with congenital CDH, DINGER et al. [17] demonstrated that FRC increased over time depending on PEEP and suctioning of the chest tube. The present FRC and Cresp data are similar to those reported by DINGER et al. [17]; however, we did not change the PEEP after surgery and chest tubes are not routinely inserted due to side-effects [4]. DiNGER et al. [17] explained the increase in FRC in CDH infants after surgery as an over-distension of hypoplastic lungs. However, FEHRENBACH et al. [18] and WEIBEL [19] described lung growth following pneumonectomy in adult mice as an effect of neoalveolarisation. It remains to be seen which of these effects is responsible for the FRC gain in our
$\mathrm{CDH}$ infants following surgical repair and further study is necessary.

At the time of extubation, the differences in lung function measurements between $\mathrm{CDH}$ and non-CDH infants had reduced, yet still remained. The observed faster increase in FRC compared with Cresp in CDH infants agrees with a recent study by ROEHR et al. [20] showing that despite apparently well-inflated lungs, $\mathrm{CDH}$ patients had worse tidal breathing parameters and lower Cresp after discharge compared with non-CDH patients. Thoracic and abdominal surgery infants had similar FRCs at extubation $(19.04 \pm 6.0$ and $18.88 \pm$ $4.0 \mathrm{~mL} \cdot \mathrm{kg}^{-1}$, respectively). Although all infants were successfully extubated and the neuromuscular blockade was removed, the FRC values were slightly lower than that reported by vON UNGERN-STERNBERG et al. [8] in intubated infants prior to anaesthetic procedures $\left(21.3 \pm 4.7 \mathrm{~mL} \cdot \mathrm{kg}^{-1}\right)$. However, the infants in the present study were younger and lighter than those in the study by VON UNGERN-STERNBERG et al. [8], and the present FRC values are consistent with those for ventilated pre-term infants [21, 22] and nonventilated full-term control infants $\left(18.4 \mathrm{~mL} \cdot \mathrm{kg}^{-1}\right)$ [23]

Performing MBWO techniques in ventilated infants is difficult because the measurements are susceptible to any ET leakage $[24,25]$. While this problem can be easily overcome in

TABLE 3 Development of pulmonary parameters after surgery for the three patient groups

\begin{tabular}{|c|c|c|c|c|}
\hline \multicolumn{5}{|l|}{ Thoracic surgery } \\
\hline $\mathrm{FRC} \mathrm{mL} \cdot \mathrm{kg}^{-1}$ & $16.38 \pm 4.0$ & $13.89 \pm 3.9^{*}$ & $19.04 \pm 6.0^{*}$ & 0.001 \\
\hline $\mathrm{LCl}$ & $9.25 \pm 2.25$ & $10.42 \pm 1.79^{*}$ & $8.67 \pm 2.02$ & 0.001 \\
\hline$M_{1} / M_{0}$ & $2.21 \pm 0.48$ & $2.46 \pm 0.42^{\star}$ & $2.07 \pm 0.5$ & 0.003 \\
\hline $\mathrm{AMDN}_{2}$ & $3.46 \pm 2.07$ & $3.85 \pm 2.82$ & $2.84 \pm 1.02$ & 0.325 \\
\hline \multicolumn{5}{|l|}{ Abdominal surgery } \\
\hline Cresp $\mathrm{mL} \cdot \mathrm{cmH}_{2} \mathrm{O}^{-1} \cdot \mathrm{kg}^{-1}$ & $0.46 \pm 0.14$ & $0.37 \pm 0.08$ & $0.55 \pm 0.16^{\star *}$ & 0.001 \\
\hline $\mathrm{FRC} \mathrm{mL} \cdot \mathrm{kg}^{-1}$ & $17.12 \pm 3.9$ & $12.66 \pm 4.3^{*}$ & $18.88 \pm 4.0$ & 0.001 \\
\hline $\mathrm{LCl}$ & $9.7 \pm 1.3$ & $10.57 \pm 2.31$ & $9.07 \pm 0.97$ & 0.177 \\
\hline \multicolumn{5}{|l|}{ Surgery of $\mathrm{CDH}$} \\
\hline Cresp $\mathrm{mL} \cdot \mathrm{cmH}_{2} \mathrm{O}^{-1} \cdot \mathrm{kg}^{-1}$ & $0.25 \pm 0.10$ & $0.26 \pm 0.09$ & $0.29 \pm 0.09$ & 0.221 \\
\hline $\mathrm{FRC} \mathrm{mL} \cdot \mathrm{kg}^{-1}$ & $8.99 \pm 2.07$ & $11.5 \pm 2.92^{*}$ & $13.7 \pm 3.61$ ** & 0.001 \\
\hline $\mathrm{LCl}$ & $11.2 \pm 1.21$ & $9.78 \pm 0.77^{*}$ & $9.24 \pm 1.08^{* *}$ & 0.005 \\
\hline$M_{1} / M_{0}$ & $2.69 \pm 0.36$ & $2.34 \pm 0.19 *$ & $2.20 \pm 0.25^{\star *}$ & 0.006 \\
\hline $\mathrm{M}_{2} / \mathrm{M}_{0}$ & $14.6 \pm 3.65$ & $11.1 \pm 1.88^{*}$ & $9.91 \pm 2.09^{* *}$ & 0.005 \\
\hline $\mathrm{AMDN}_{1}$ & $1.57 \pm 0.34$ & $1.20 \pm 0.36^{*}$ & $0.98 \pm 0.19^{\star \star *}$ & 0.005 \\
\hline $\mathrm{AMDN}_{2}$ & $5.20 \pm 2.28$ & $3.06 \pm 1.93$ & $2.09 \pm 0.91$ & 0.009 \\
\hline
\end{tabular}

Data are presented as group mean $\pm \mathrm{SD}$, unless otherwise indicated. $\mathrm{CDH}$ : congenital diaphragmatic hernia; Cresp: respiratory compliance; FRC: functional residual capacity; LCl: lung clearance index; $M_{1} / M_{0}$ : first-to-zeroth moment ratio; $M_{2} / M_{0}$ : second-to-zeroth moment ratio; $A M D N_{1}$ and $A M D N_{2}$ : alveolar mean dilution numbers 1 and 2 , respectively. ${ }^{*}: p<0.05 ;{ }^{* *}: p<0.01$, when compared with measurements before surgery. Statistically significant values after Bonferroni correction are indicated in bold. 

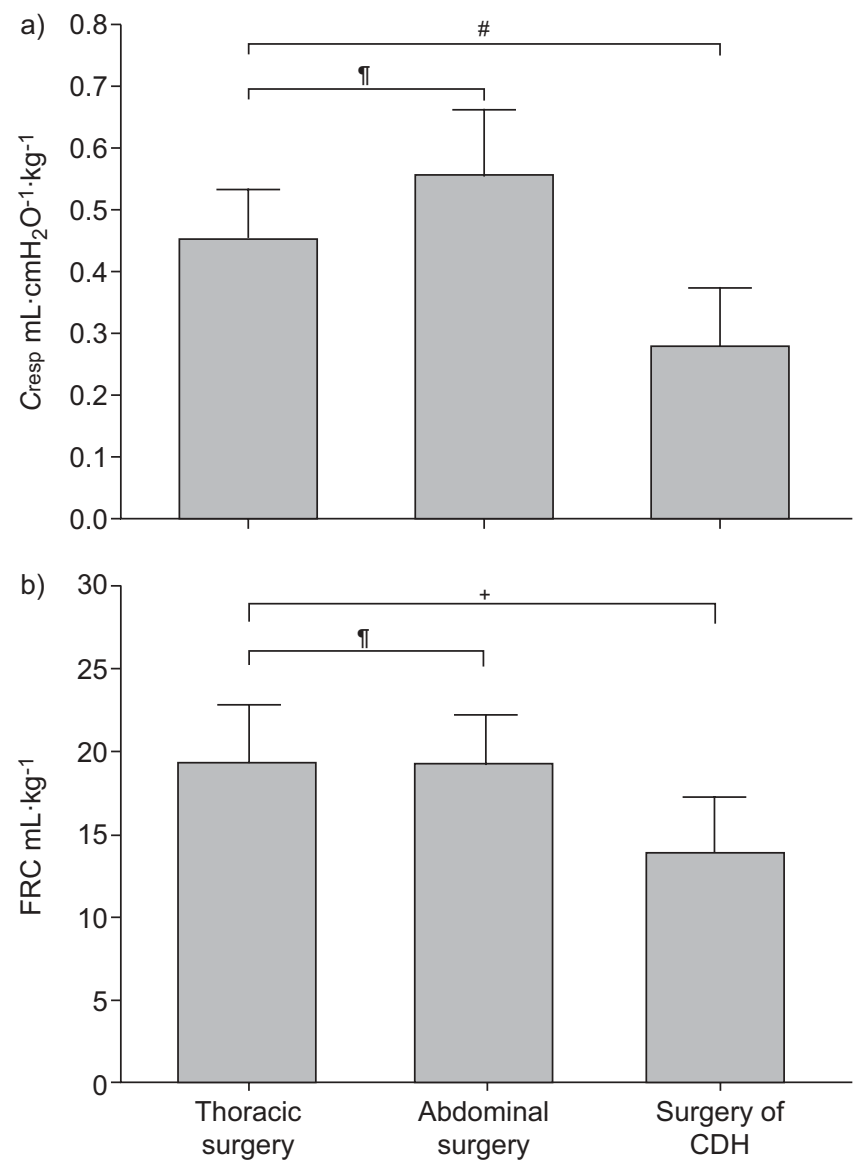

FIGURE 3. a) Respiratory compliance (Cresp) and b) functional residual capacity (FRC) in infants before extubation. $\mathrm{CDH}$ : congenital diaphragmatic hernia. ${ }^{\#}: p=0.001 ;{ }^{\bullet}$ : nonsignificant; ${ }^{+}: p=0.018$.

ventilated older patients by using cuffed ETs [8], uncuffed ETs are advised in neonates both to protect airways and to avoid subglottic stenosis [26]. In our study, we could exclude a substantial effect of ET leakage on FRC measurements. During measurement we tried to avoid any ET leakage; if necessary the head position was changed. In a previous in vitro study, we found that the absolute value of the relative FRC error was $<3 \%$ for ET leakages $<20 \%$ and $6 \%$ for ET leakages $<40 \%$. In our study, the ET leakage was $<20 \%$ in $95 \%$ of all infants and ET leakages of $40 \%$ were never exceeded.

Tracer gas MBWO characteristics (e.g. VD,app, gas sensors used, properties of tracer gases and number of evaluated breathing cycles during tracer gas wash-in and washout) are also highly method dependent. Most MBWO measurements in ventilated newborns are performed using custom-made equipment and nitrogen [27], helium [28] or sulfur hexafluoride (SF6) [7] as tracer gases. The commercial system for MBWO in ventilated patients [9] used by VON UNGERN-STERNBERG et al. [8] is based on ultrasound spirometry with SF6 as the tracer gas. That equipment has a high $V \mathrm{D}$,app and a bulky and heavy measuring head, and its use was shown to be feasible predominantly in ventilated older infants or preschool children aged from 13 months to 7 yrs [29-31]. By comparison, our HFP measuring head was designed for use in small lungs and is smaller and lighter. While HFP and SF6 are both inert gases, the former has a higher molecular weight (170.03 versus $\left.146.05 \mathrm{~g} \cdot \mathrm{mol}^{-1}\right)$, water solubility $\left(0.23\right.$ versus $\left.0.04561 \mathrm{~g} \cdot \mathrm{L}^{-1}\right)$ and specific (air=1) gravity (5.9 versus 5.114$)$ and a lower vapour pressure (4 versus 21.5 bar). Furthermore, tracer gas concentrations are lower for HFP compared to SF6 (0.8 versus $4 \%[9,32])$. We recently investigated the in vitro accuracy of HFP-MBWO in ventilated piglets [10] and found that it allowed for reproducible measurements of FRC and VI indices, and no relevant accumulation of HFP was observed [33].

The present study found that HFP-MBWO was a valuable tool for monitoring the effect of surgery on lung function. First, a limitation of the study was the relatively low number of patients in each treatment group, which may have limited the statistical power for comparing differences in lung function and increased the risk of the type II error. The calculated sample size was only reached for non-CDH infants. Secondly, the still relatively high $V \mathrm{D}$,app of the combined flow and HFP sensor meant that only patients with $V$ T values $>10 \mathrm{~mL}$ could be investigated, which reduced the number of eligible patients. Hopefully, technical progress and increased efforts by the manufacturers will lead to new, lightweight mainstream sensors with a $V$ D,app $<1 \mathrm{~mL}$ that will enable reliable measurements even in premature infants. Thirdly, the extent to which FRC monitoring could be used to optimise ventilator settings and to realise the "open lung concept" [34] remains unknown, even in these small patients.

In conclusion, the HFP-MBWO is a suitable technique to assess the effect of thoraco-abdominal surgery on the lung. The study has shown that infants with $\mathrm{CDH}$ have low FRC values and impaired gas mixing before surgery, which improves, but does not normalise, thereafter. In contrast, infants receiving thoracic surgery showed a temporary decline after surgery whereas, in infants receiving abdominal surgery, little variation took place. These changes were not reflected in mechanical or ventilatory variables. A prerequisite for clinical use of HFP-MBWO is that the measuring heads be miniaturised so that measurements in premature infants are possible and that this technique is integrated into the standard monitoring of neonatal ventilators.

\section{SUPPORT STATEMENT}

H. Proquitté was supported by a grant totalling $€ 2,000$ from the Charité Universitätsmedizin Berlin (Berlin, Germany).

\section{STATEMENT OF INTEREST}

A statement of interest for H. Proquitté, R.R. Wauer and G. Schmalisch can be found at www.erj.ersjournals.com/misc/statements.dtl

\section{ACKNOWLEDGEMENTS}

This research was presented at the annual meeting of the GNPI in Zurich 2008, and at the annual meeting of the European Respiratory Society in Berlin 2008.

H. Proquitté, O. Freiberger., S. Yilmaz and C.C. Roehr conducted the measurements; H. Proquitté., G. Schmalisch and R.R. Wauer planned and calculated the study. C. Bamberg and P. Degenhardt were responsible for pre-natal diagnosis and surgery, respectively. The paper was written by H. Proquitté and G. Schmalisch, who was responsible for statistics.

We thank S. Butler, Coogee, Australia, for meticulous language editing of the text. 


\section{REFERENCES}

1 el-Zein C, Ilbawi MN. Recent advances in neonatal cardiac surgery. World J Surg 2008; 32: 340-345.

2 Zannini L, Borini I. State of the art of cardiac surgery in patients with congenital heart disease. J Cardiovasc Med 2007; 8: 3-6.

3 Islam S. Clinical care outcomes in abdominal wall defects. Curr Opin Pediatr 2008; 20: 305-310.

4 Boloker J, Bateman DA, Wung JT, et al. Congenital diaphragmatic hernia in 120 infants treated consecutively with permissive hypercapnea/spontaneous respiration/elective repair. J Pediatr Surg 2002; 37: 357-366.

5 Schmalisch G, Proquitte H, Roehr CC, et al. The effect of changing ventilator settings on indices of ventilation inhomogeneity in small ventilated lungs. BMC Pulm Med 2006; 6: 20.

6 Riou Y, Storme L, Leclerc F, et al. Comparison of four methods for measuring elevation of FRC in mechanically ventilated infants. Intensive Care Med 1999; 25: 1118-1125.

7 Vilstrup CT, Bjorklund LJ, Larsson A, et al. Functional residual capacity and ventilation homogeneity in mechanically ventilated small neonates. J Appl Physiol 1992; 73: 276-283.

8 von Ungern-Sternberg BS, Hammer J, Schibler A, et al. Decrease of functional residual capacity and ventilation homogeneity after neuromuscular blockade in anesthetized young infants and preschool children. Anesthesiology 2006; 105: 670-675.

9 Schibler A, Henning R. Measurement of functional residual capacity in rabbits and children using an ultrasonic flow meter. Pediatr Res 2001; 49: 581-588.

10 Proquitte H, Kusztrich A, Auwarter V, et al. Functional residual capacity measurement by heptafluoropropane in ventilated newborn lungs: in vitro and in vivo validation. Crit Care Med 2006; 34: 1789-1795.

11 Shao H, Sandberg K, Sjoqvist BA, et al. Moment analysis of multibreath nitrogen washout in healthy preterm infants. Pediatr Pulmonol 1998; 25: 52-58.

12 Peralta CF, Jani J, Cos $\mathrm{T}$, et al. Left and right lung volumes in fetuses with diaphragmatic hernia. Ultrasound Obstet Gynecol 2006; 27: 551-554.

13 Matthews IL, Kaldestad RH, Bjornstad PG, et al. Preoperative lung function in newborn infants with univentricular hearts compared with healthy controls. Acta Paediatr 2007; 96: 44-48.

14 Nakayama DK, Mutich R, Motoyama EK. Pulmonary dysfunction in surgical conditions of the newborn infant. Crit Care Med 1991; 19: 926-933.

15 DiCarlo JV, Raphaely RC, Steven JM, et al. Pulmonary mechanics in infants after cardiac surgery. Crit Care Med 1992; 20: 22-27.

16 Dimitriou G, Greenough A, Giffin F, et al. Temporary impairment of lung function in infants with anterior abdominal wall defects who have undergone surgery. J Pediatr Surg 1996; 31: 670-672.

17 Dinger J, Peter-Kern M, Goebel P, et al. Effect of PEEP and suction via chest drain on functional residual capacity and lung compliance after surgical repair of congenital diaphragmatic hernia: preliminary observations in 5 patients. I Pediatr Surg 2000; 35: 1482-1488.

18 Fehrenbach H, Voswinckel R, Michl V, et al. Neoalveolarisation contributes to compensatory lung growth following pneumonectomy in mice. Eur Respir J 2008; 31: 515-522.
19 Weibel ER. How to make an alveolus. Eur Respir J 2008; 31: 483-485.

20 Roehr CC, Proquitté H, Jung A, et al. Impaired somatic growth and delayed lung development in infants with congenital diaphragmatic hernia - evidence from a 10-year, single center prospective follow-up study. J Pediatr Surg 2009; 44: 1309-1314.

21 Dimitriou G, Greenough A, Laubscher B. Appropriate positive end expiratory pressure level in surfactant-treated preterm infants. Eur J Pediatr 1999; 158: 888-891.

22 Dinger J, Topfer A, Schaller P, et al. Functional residual capacity and compliance of the respiratory system after surfactant treatment in premature infants with severe respiratory distress syndrome. Eur J Pediatr 2002; 161: 485-490.

23 Hulskamp G, Lum S, Stocks J, et al. Association of prematurity, lung disease and body size with lung volume and ventilation inhomogeneity in unsedated neonates: a multicentre study. Thorax 2009; 64: 240-245.

24 Fox WW, Schwartz JG, Shaffer TH. Effects of endotracheal tube leaks on functional residual capacity determination in intubated neonates. Pediatr Res 1979; 13: 60-64.

25 Seidenberg J, Homberger J, von der Hardt H. Effect of endotracheal tube leakage on functional residual capacity determination by nitrogen washout method in a small-sized lung model. Pediatr Pulmonol 1994; 17: 106-112.

26 Bernstein G, Knodel E, Heldt GP. Airway leak size in neonates and autocycling of three flow-triggered ventilators. Crit Care Med 1995; 23: 1739-1744.

27 Edberg KE, Sandberg K, Silberberg A, et al. Lung volume, gas mixing, and mechanics of breathing in mechanically ventilated very low birth weight infants with idiopathic respiratory distress syndrome. Pediatr Res 1991; 30: 496-500.

28 Goldsmith LS, Greenspan JS, Rubenstein SD, et al. Immediate improvement in lung volume after exogenous surfactant: alveolar recruitment versus increased distention. I Pediatr 1991; 119: 424-428.

29 von Ungern-Sternberg BS, Frei FJ, Hammer J, et al. Impact of depth of propofol anaesthesia on functional residual capacity and ventilation distribution in healthy preschool children. $\mathrm{Br} J$ Anaesth 2007; 98: 503-508.

30 von Ungern-Sternberg BS, Regli A, Frei FJ, et al. A deeper level of ketamine anaesthesia does not affect functional residual capacity and ventilation distribution in healthy preschool children. Paediatr Anaesth 2007; 17: 1150-1155.

31 von Ungern-Sternberg BS, Hammer J, Frei FJ, et al. Prone equals prone? Impact of positioning techniques on respiratory function in anesthetized and paralyzed healthy children. Intensive Care Med 2007; 33: 1771-1777.

32 Pillow JJ, Ljungberg H, Hulskamp G, et al. Functional residual capacity measurements in healthy infants: ultrasonic flow meter versus a mass spectrometer. Eur Respir J 2004; 23: 763-768.

33 Auwarter V, Proquitte H, Schmalisch G, et al. Determination of $1,1,1,2,3,3,3$-heptafluoropropane (HFP) in blood by headspace gas chromatography-mass spectrometry. J Anal Toxicol 2005; 29: 574-576.

34 Lachmann B. Open up the lung and keep the lung open. Intensive Care Med 1992; 18: 319-321. 